\title{
Estimating the Economic Burden of Premature Mortality Caused by Cancer in Iran: 2006-2010
}

\author{
Behzad Karami-Matin', Farid Najafi ${ }^{1}$, Satar Rezaei ${ }^{1}$, Ardashir Khosravi ${ }^{3,4}$, \\ Moslem Soofi ${ }^{2 *}$
}

\begin{abstract}
Background: Cancer is currently one of the main public health problems all over the world and its economic burden is substantial both for health systems and for society as a whole.To inform priorities for cancer control, we here estimated years of potential life lost (YPLL) and productivity losses due to cancer-related premature mortality in Iran from 2006 to 2010. Materials and Methods: The number of cancer deaths by sex and age groups for top ten leading cancers in Iran were obtained from the Ministry of Health and Medical Education. To estimate theYPLL and the cost of productivity loss due to cancer-related premature mortality, the life expectancy method and the human capital approach were used, respectively. Results: There were 138,228 cancer-related deaths in Iran (without Tehran province) of which $76 \%(106,954)$ were attributable to the top 10 ranked cancers. Some $63 \%$ of total cancer-related deaths were of males. The top 10 ranked cancers resulted in 106,766,942 YPLL in total, 64,171,529 $(60 \%)$ in males and 42,595,412 (40\%) in females. The estimated YPPLL due to top 10 ranked cancers was $58,581,737$ during the period studied of which $32,214,524(54 \%)$ was accounted for in males.The total cost of lost productivity caused by premature deaths because of top 10 cancers was 1.68 billion dollars (US\$) from 2006 to 2010, ranging from 251 million dollars in 2006 to 283 million dollars in 2010 . Conclusions: This study showed that the economic burden of premature mortality attributable to cancer is significant for Iranian society. The findings provide useful information about the economic impact of cancer for health system policy/ decision makers and should facilitate planning of preventive intervention and effective resource allocation.
\end{abstract}

Keywords: Economic burden - cancer-related premature mortality - years of life lost - productivity costs - Iran

Asian Pac J Cancer Prev, 17 (4), 2131-2136

\section{Introduction}

Cancer is currently one of the main leading cause of death in both developed and developing countries (Jemal et al., 2011). Based on GLOBCAN databases, an estimated 14.1 million new cancer cases and about 8.2 million deaths due to cancer occurred in 2012 worldwide which $53 \%$ of them accounts for developing countries(Torre, Bray et al., 2015). In Iran, cancer is one of the main public health problem for policy-makers and planner in health sector. An about 53,350 deaths caused by cancer 53,350 occurred in 2012 and is expected to will reach to 58,087 deaths in 2015. In addition, cancer is the third leading cause of deaths after coronary heart disease and road traffic injuries (Naghavi et al., 2009, Kambiz et al., 2011).

Cancer incidence will continue to rise because of the growth in life expectancy, increase in the proportion of the elderly population and size of population over the world (Jemal et al., 2011). In recent years, deaths due to cancer has decreased in developed countries as a result of improvement in preventive and therapeutic interventions, whereas in developing countries such as Iran, it has significantly risen (Jemal et al., 2010, Khorasani et al., 2014). Then, it is necessary to conduct the preventive and therapeutic interventions in order to reduce the burden of cancer in developing countries like Iran. Due to limitation of health resources, it is necessary for health policy-makers to prioritize the cancer control interventions (Kim et al., 2013).

One of the main ways in this issue is the estimating economic burden of cancer, including healthcare expenditures and cost of lost productivity due to mortality and morbidity. Based on previous studies, the cost of cancer- related premature mortality accounts for 70 to 85 $\%$ of the total cost (Insinga 2006, Jonsson and Wilking, 2007; Bradley et al., 2008, Ortiz et al., 2010; Hanly and

${ }^{1}$ Research Center for Environmental Determinants of Health, ${ }^{2}$ Social Development and Health Promotion Research Center, Kermanshah University of Medical Sciences, Kermanshah, ${ }^{3}$ Deputy of Health, Ministry of Health and Medical Education, ${ }^{4}$ NonCommunicable Diseases Research Center, Endocrinology and Metabolism Population Sciences Institute, Tehran University of Medical Sciences, Tehran, Iran*For correspondence: moslemsoofi@yahoo.com 
Sharp, 2014). Majority of conducted previous studies in Iran estimate the direct cost of cancer (Akbarzadehbaghban et al., 2009, Bazyar et al., 2012). Previous studies have estimated the total cost of breast cancer (Daroudi et al., 2015) and the total cost of cancer deaths attributable to smoking (Rezaei et al., 2015).

To the best of our knowledge, no study quantify the costs of cancer-related premature mortality in Iran at the national level for more than one year. The current study aimed to estimate the economic burden of cancer-related premature mortality in Iran over the five years from 2006 to 2010 .

\section{Materials and Methods}

Data on deaths caused by top 10 cancers by sex and age groups (under one, 1-4, 5-9, 10-14, 15-19, 20-24, 24-29, 30-34, 35-39, 40- 44, 45-49, 50-59. 60-64, 65-69, 70- 74, 75-79, 80-84 and 85+) for 29 provinces (data for Tehran province for the studied period is not available) were retrieved from the Ministry of Health and Medical Education (MoHME) over the five years from 2006 to 2010.To estimate the average life expectancy for each age group, Iran life table from the World Health Organization was used. Data on age- and sex-specific wages for the studied period came from the Iranian Ministry of Cooperation Labor and Social Welfare. Also, the data on age and sex-specific employment and housekeeping rate for the studied period were obtained from the Iranian Statistical Center (ISC). Because of there weren't any data about wages for the housekeeping activity in Iran, the minimum daily wage approved by the Iranian Ministry of Cooperation, Labor and Social Welfare was used for the females housekeeping activities.

To estimate the quantify burden of cancers and its impact on society, two measures including years of potential life lost (YPLL) and cost of productivity loss (CPL) were used. The YPLL was calculated by the life expectancy methods. We assumed that all of deaths in each age group occurred in the mid-point of that age group. So, to calculate of YPLL, the number of deaths in each group was multiplied by the average of remaining life expectancy. Based on previous studies, to estimate the CPL, the human capital approach was used (Insinga 2006, Bradley et al., 2008; Hanly and Sharp, 2014). The CPL was estimated as follow: first, the YPLL according to the previous section was estimated, only in terms of CPL, we disregarded any deaths beyond 65 years and less than 15 years. Then, the estimated YPLL was multiplied by age and sex-specific annual wages from age of deaths until the retirement age. The estimated CPL was adjusted based on the employment and housekeeping rate. In addition, to obtain the present value the future costs were discounted at $3 \%$ per year. CPL for each death were summed across age groups by sex and cancer site (Khorasani et al., 2014; Rezaei et al., 2015).

\section{Results}

During 2006-2010, there were 138,228 cancer-related deaths in Iran (without Tehran province) which $76 \%$ of them $(106,954)$ were attributable to the top 10 ranked cancers. $63 \%$ of total cancer-related deaths were in male. The main causes of cancer-related deathsweregastric,lung and prostate in the males, whereas they were gastric, breast and lung in the females. For the whole of period studied, gastric cancer was the most common cause of death in males, females and both sexes combined.The total number of deaths caused by cancer increased by $10 \%$ in males and by $22 \%$ in females (Table 1 ). There were 42,351 deaths between 15 and 64 (working-age range), related to the top 10 ranked cancersduring the period analysed and $56 \%$ of

Table 1. Numbers of Deaths Due to the top 10 Ranked Cancers by Sex in Iran During 2006-2010

\begin{tabular}{|c|c|c|c|c|c|c|}
\hline ICD COD & Cancer site & 2006 & 2007 & 2008 & 2009 & 2010 \\
\hline \multicolumn{7}{|l|}{ Male } \\
\hline $\mathrm{C} 15$ & Esophagus & 944 & 931 & 849 & 889 & 911 \\
\hline C16 & Stomach & 3,680 & 3,790 & 3,777 & 3,740 & 3,735 \\
\hline $\mathrm{C} 17$ & Small intestine & 433 & 413 & 491 & 500 & 513 \\
\hline $\mathrm{C} 18$ & Colon & 499 & 586 & 639 & 684 & 653 \\
\hline $\mathrm{C} 22$ & Liver & 1,425 & 1,453 & 1,505 & 1,566 & 1,607 \\
\hline C32 & Laryngeal & 539 & 566 & 595 & 593 & 649 \\
\hline C33-C34 & Lung & 2,353 & 2,515 & 2,571 & 2,514 & 2,718 \\
\hline C61 & Prostate & 1,296 & 1,479 & 1,510 & 1,572 & 1,706 \\
\hline $\mathrm{C} 70-\mathrm{C} 72$ & Brain \& CNS & 792 & 882 & 848 & 863 & 898 \\
\hline C95-C96 & Leukaemias of unspecified cell type & 960 & 869 & 861 & 928 & 821 \\
\hline \multicolumn{7}{|l|}{ Female } \\
\hline $\mathrm{C} 15$ & Esophagus & 619 & 624 & 663 & 614 & 631 \\
\hline $\mathrm{C} 16$ & Stomach & 1,849 & 1,905 & 1,824 & 1,853 & 1,889 \\
\hline $\mathrm{C} 17$ & Small intestine & 287 & 311 & 313 & 314 & 324 \\
\hline $\mathrm{C} 18$ & Colon & 337 & 433 & 470 & 435 & 461 \\
\hline $\mathrm{C} 22$ & Liver & 923 & 1,036 & 1,109 & 1,029 & 1,199 \\
\hline C33-C34 & Lung & 993 & 1,059 & 1,068 & 1,089 & 1,138 \\
\hline $\mathrm{C} 50$ & Breast & 962 & 1,086 & 1,122 & 1,124 & 1,283 \\
\hline C53 & cervix & 23 & 262 & 276 & 267 & 300 \\
\hline C70-C72 & Brain \& CNS & 564 & 659 & 640 & 612 & 676 \\
\hline C95-C96 & Leukaemias of unspecified cell type & 37 & 552 & 544 & 527 & 519 \\
\hline
\end{tabular}


Table 2. Estimated YPLL for the Top 10 Ranked Cancers by Sex in Iran during 2006-2010

\begin{tabular}{|c|c|c|c|c|c|c|}
\hline ICD COD & Cancer site & 2006 & 2007 & 2008 & 2009 & 2010 \\
\hline \multicolumn{7}{|l|}{$\overline{\text { Male }}$} \\
\hline $\mathrm{c} 15$ & Esophagus & 889,295 & 856,037 & $3,497,347$ & 808,694 & 826,658 \\
\hline c16 & Stomach & $3,452,613$ & $3,556,324$ & $2,484,936$ & $3,474,500$ & $3,460,584$ \\
\hline $\mathrm{C} 17$ & Small intestine & 420,430 & 366,937 & $1,114,812$ & 480,050 & 490,382 \\
\hline $\mathrm{C} 18$ & Colon & 495,921 & 586,502 & $1,471,622$ & 698,852 & 649,030 \\
\hline $\mathrm{C} 22$ & Liver & $1,398,365$ & $1,372,498$ & 885,379 & $1,547,447$ & $1,555,607$ \\
\hline $\mathrm{C} 32$ & Laryngeal & 537,868 & 561,802 & 789,821 & 594,637 & 644,580 \\
\hline C33-C34 & Lung & $2,302,693$ & $2,434,168$ & 904,506 & $2,418,865$ & $2,649,259$ \\
\hline C61 & Prostate & 981,995 & $1,100,270$ & 624,268 & $1,133,122$ & $1,235,948$ \\
\hline C70-C72 & Brain \& CNS & 871,826 & 950,967 & 582,424 & 949,187 & 990,780 \\
\hline C95-C96 & Leukaemias of unspecified cell type & 991,608 & 860,296 & 477,582 & 943,521 & 798,700 \\
\hline \multicolumn{7}{|l|}{ Female } \\
\hline $\mathrm{c} 15$ & Esophagus & 624,943 & 634,863 & 651,742 & 606,873 & 625,733 \\
\hline c16 & Stomach & $1,878,272$ & $1,888,272$ & $1,844,118$ & $1,825,545$ & $1,910,794$ \\
\hline $\mathrm{C} 17$ & Small intestine & 308,182 & 318,182 & 339,567 & 318,363 & 339,824 \\
\hline $\mathrm{C} 18$ & Colon & 357,620 & 367,620 & 494,694 & 476,527 & 492,600 \\
\hline $\mathrm{C} 22$ & Liver & 982,665 & 986,609 & $1,151,351$ & $1,083,388$ & $1,231,960$ \\
\hline C33-C34 & Lung & $1,042,846$ & $1,142,905$ & $1,108,167$ & $1,133,017$ & $1,197,345$ \\
\hline C50 & Breast & $1,289,246$ & $1,389,429$ & $1,482,823$ & $1,479,704$ & $1,702,422$ \\
\hline C53 & cervix & 278,494 & 298,395 & 322,921 & 345,702 & 354,935 \\
\hline $\mathrm{C} 70-\mathrm{C} 72$ & Brain \& CNS & 661,974 & 691,887 & 734,790 & 714,029 & 801,926 \\
\hline C95-C96 & Leukaemias of unspecified cell type & 625,941 & 605,941 & 595,944 & 579,956 & 548,273 \\
\hline
\end{tabular}

Table 3. Estimated YPPLL for the Top 10 Ranked Cancers by Sex in Iran during 2006-2010

\begin{tabular}{ccccccc}
\hline ICD COD & Cancer site & 2006 & 2007 & 2008 & 2009 & 2010 \\
\hline Male & & & & & & \\
c15 & Esophagus & 413,779 & 380,630 & $1,549,353$ & 354,741 & 374,040 \\
c16 & Stomach & $1,536,291$ & $1,637,184$ & $1,277,131$ & $1,614,315$ & $1,644,043$ \\
C17 & Small intestine & 222,702 & 145,923 & 245,956 & 263,403 & 261,927 \\
C18 & Colon & 280,409 & 347,638 & 769,303 & 404,318 & 364,789 \\
C22 & Liver & 734,841 & 667,203 & 612,728 & 857,822 & 839,350 \\
C32 & Laryngeal & 283,266 & 303,039 & 382,075 & 332,722 & 370,831 \\
C33-C34 & Lung & $1,170,056$ & $1,243,424$ & 626,582 & $1,263,577$ & $1,463,828$ \\
C61 & Prostate & 215,273 & 238,627 & 332,210 & 226,081 & 268,677 \\
C70-C72 & Brain \& CNS & 637,152 & 680,927 & 320,604 & 693,068 & 725,438 \\
C95-C96 & Leukaemias of unspecified cell type & 673,769 & 572,183 & 252,610 & 631,808 & 506,860 \\
Female & & & & & & \\
c15 & Esophagus & 307,299 & 308,198 & 292,402 & 290,004 & 308,165 \\
c16 & Stomach & 912,641 & 902,632 & 908,077 & 870,992 & 991,511 \\
C17 & Small intestine & 170,750 & 178,754 & 200,567 & 180,188 & 197,293 \\
C18 & Colon & 206,724 & 236,754 & 291,239 & 296,696 & 295,711 \\
C22 & Liver & 562,952 & 592,831 & 626,806 & 617,350 & 655,315 \\
C33-C34 & Lung & 571,881 & 581,321 & 598,772 & 629,359 & 678,045 \\
C50 & Breast & $1,096,959$ & $1,196,123$ & $1,239,704$ & $1,227,192$ & $1,451,303$ \\
C53 & cervix & 194,641 & 199,441 & 222,066 & 266,564 & 255,229 \\
C70-C72 & Brain \& CNS & 492,265 & 530,201 & 552,133 & 538,846 & 600,895 \\
C95-C96 & Leukaemias of unspecified cell type & 433,472 & 423,472 & 409,212 & 402,124 & 374,262 \\
\hline
\end{tabular}

them were in males.

The number of YPLL due to the top 10 ranked cancer-related deaths by sex from 2006 to 2010 in Iranis presented in Table 2. Thesetop 10 ranked cancers resulted in $106,766,942$ YPLL in total $64,171,529(60 \%)$ in the males and 42,595,412 (40\%) in the females. In the period analysed, the highest number of the YPLL was related to gastric cancer, followed by lung, Esophageal, liver and prostate for males, and the highest number of the YPLL for females was gastric cancer, followed by breast, lung, liver and esophagus.from 2006 to 2010, the overall number of YPLLincreased by $8 \%$ for males and by $13 \%$ for females. (Table 2)

Table 3 shows the YPPLL bysex and type of cancer for the period analyzed.The estimated YPPLL due to top 10 ranked cancers was $58,581,737$ from 2006 to 2010 which $32,214,524(54 \%)$ of them were in male. From 2006 to 2010 , the total number of YPPLL increased by $9 \%$ for males and by $15 \%$ for females.Among males, the highest number for YPPLL was gastric cancer, followed by lung and liver. For females, the highest number for PYPLL was breast cancer, followed by gastric cancer 
Table 4. Estimated Premature Mortality Costs Due to TopTen Cancers by Sex in Iran during 2006-2010, (US \$)

\begin{tabular}{|c|c|c|c|c|c|c|}
\hline ICD COD & Cancer site & 2006 & 2007 & 2008 & 2009 & 2010 \\
\hline \multicolumn{7}{|l|}{ Male } \\
\hline c15 & Esophagus & $8,808,830$ & $10,625,327$ & $12,715,898$ & $11,239,553$ & $8,865,640$ \\
\hline c16 & Stomach & $39,136,136$ & $46,647,752$ & $45,482,655$ & $50,260,028$ & $43,152,545$ \\
\hline $\mathrm{C} 17$ & Small intestine & $6,861,558$ & $3,471,005$ & $9,669,948$ & $11,004,909$ & $8,881,256$ \\
\hline $\mathrm{C} 18$ & Colon & $9,004,471$ & $11,314,383$ & $224,032,229$ & $16,016,603$ & $11,568,005$ \\
\hline $\mathrm{C} 22$ & Liver & $24,508,124$ & $20,861,564$ & $28,259,921$ & $31,546,709$ & $23,970,587$ \\
\hline C32 & Laryngeal & $7,805,355$ & $8,209,518$ & $9,961,959$ & $11,549,587$ & $10,080,893$ \\
\hline C33-C34 & Lung & $31,052,671$ & $36,452,553$ & $43,632,251$ & $44,484,194$ & $41,155,198$ \\
\hline C61 & Prostate & $3,931,417$ & $4,406,357$ & $6,724,090$ & $5,470,572$ & $5,451,759$ \\
\hline C70-C72 & Brain \& CNS & $30,303,625$ & $34,653,710$ & $36,934,492$ & $41,263,102$ & $35,439,514$ \\
\hline C95-C96 & Leukaemias of unspecified cell type & $41,173,727$ & $37,458,991$ & $47,783,088$ & $44,589,055$ & $34,550,052$ \\
\hline \multicolumn{7}{|l|}{ Female } \\
\hline $\mathrm{c} 15$ & Esophagus & $1,778,344$ & $2,921,943$ & $2,698,421$ & $2,447,410$ & $1,968,421$ \\
\hline c16 & Stomach & $6,714,114$ & $9,142,011$ & $9,394,984$ & $9,473,632$ & $8,120,992$ \\
\hline $\mathrm{C} 17$ & Small intestine & $1,894,531$ & $1,687,153$ & $2,687,222$ & $2,180,563$ & $1,801,678$ \\
\hline $\mathrm{C} 18$ & Colon & $1,766,437$ & $2,827,791$ & $3,090,542$ & $3,860,440$ & $3,104,044$ \\
\hline $\mathrm{C} 22$ & Liver & $4,967,920$ & $5,059,156$ & $7,195,292$ & $7,262,528$ & $5,548,064$ \\
\hline C33-C34 & Lung & $4,384,472$ & $6,291,862$ & $7,521,633$ & $7,135,474$ & $6,119,040$ \\
\hline $\mathrm{C} 50$ & Breast & $10,309,944$ & $13,543,183$ & $15,347,129$ & $16,396,540$ & $14,639,443$ \\
\hline C53 & cervix & $1,894,531$ & $2,499,836$ & $2,670,796$ & $4,928,843$ & $2,822,108$ \\
\hline $\mathrm{C} 70-\mathrm{C} 72$ & Brain \& CNS & $6,997,365$ & $8,534,069$ & $10,313,896$ & $10,040,560$ & $8,235,163$ \\
\hline $\mathrm{C} 95-\mathrm{C} 96$ & Leukaemias of unspecified cell type & $8,303,563$ & $10,413,992$ & $10,134,954$ & $10,957,881$ & $6,720,549$ \\
\hline
\end{tabular}

and lung. (Table 3)

The total cost of productivity loss caused by premature deaths because of top 10 cancers was 1.68 billion dollars (US\$) from 2006 to 2010, ranging from 251 million dollars in 2006 to 283 million dollars in 2010. From 2006 to 2010 , the CPL increased by $10 \%$ in males and by $18 \%$ for females. Among males, the main contributors of total cost of lost productivity were colon, gastric, Leukaemias of unspecified cell type, long and brain, respectively. For females the highest CPL was due to breast cancer followed by Leukaemias of unspecified cell type, brain, gastric and lung cancer. The percentage of the total costs due to productivity losses for 10 main cancers was 81.2 $\%$ in males and $18.8 \%$ in female (Table 4 ).

For the whole studied period, the average premature mortality cost per death for both sexes combined was US $\$ 420,842$. It was $\$ 331,733$ for males and $\$ 88,748$ for females. In this period, the most costly cause per death in males was colon cancer $(\$ 1,113,825$ per death) followed by Leukaemias of unspecified $(\$ 454,183)$, and brain $(\$$ $363,622)$. Prostate cancer was the least costly cancer per death in male $(\$ 142,361)$. Among females, the most costly cancer was leukaemias of unspecified cell type $(\$ 166,563)$ followed by brain $(\$ 121,016)$ and breast cancer $(\$ 98,335)$. The least costly cancer in females was esophageal cancer $(\$ 49,652)$.

Table 5 also shows the average premature mortality cost per YPPLL by sex from 2007 to 2010 . The average cost per YPPLL in the studied period for both sexes combined was $\$ 152$.9. It was $\$ 244.2$ for males and $\$ 61.6$ for females. Among males, in term of cost per YPPLL, like cost per death, cancer of colon and prostate cancer were most costly and least costly cancer, respectively in case of females the most costly cancer per YPPLL was Leukaemias of unspecified cell type and the least costly cancer was esophageal cancer.

\section{Discussion}

The aim of this study was to measure economic burden of premature mortalities due to cancer-related deaths in Iran between 2006 and 2010. We usednumber of mortality, YPLL, YPPLL and cost of productivity losses to quantify the burden of premature mortality caused by cancers. Based on previous studies human capital approach was used to estimate cost of productivity losses. $[5,13,15$, 18-20].

There were 138228 cancer-related deaths in Iran from 2006 to $2010,76 \%$ of them were attributable to top 10 ranked cancer.The total number of deaths caused by cancer increased by $16 \%$ for both sexes combined over the period. A study conducted by frouzanfar et al. to evaluate causes of death and morbidity in Iran, showed that more than 57\% of deaths in 2010 were caused by cardiovascular diseases and cancers and the cancer was the second most frequent cause of death(Forouzanfar MH, Sepanlou SG et al., 2014). Another study by naghavi et al. that assessed the burden of diseases in Iran showed that stomach cancer was one of top ten ranked cause of mortalityies (Naghavi et al., 2009). At global level, a study for the global burden of disease by Lozano et al. showed that 8 million deaths occurred because of cancer in 2010 which $19 \%$ of them were from trachea, bronchus and lung cancer. Their report indicated that lung cancer was one of leading cause of death at global level (Rafael et al., 2013).

In the present study the main contributors to YPLL in males, were gastric and lung cancer, while they were gastric and breast cancer in females. Similarly, in a previuos studiyin Iran stomach cancer was the second highest burden by YPLL. In addition, it showed that most important cancers in Iran are gastric cancer, lung cancer, and breast cancer (Forouzanfar et al., 2014). According to another study in Iran among males and in the both sexes 
Table 5. Premature Mortality Costs per Death/YPPLL for the TenTop Cancers in Iran, 2006-2010, (US \$)

\begin{tabular}{|c|c|c|c|c|c|c|c|}
\hline ICD COD & Cancer site & & 2006 & 2007 & 2008 & 2009 & 2010 \\
\hline \multicolumn{8}{|l|}{ Male } \\
\hline \multirow{2}{*}{$\mathrm{c} 15$} & \multirow{2}{*}{ Esophagus } & CPL/DEATH & 28,600 & 37,947 & 44,774 & 42,735 & 32,005 \\
\hline & & CPL/YPPLL & 21.3 & 27.9 & 33.2 & 31.7 & 23.7 \\
\hline \multirow[b]{2}{*}{ c16 } & \multirow{2}{*}{ Stomach } & CPL/DEATH & 34,481 & 38,776 & 39,550 & 41,988 & 35,575 \\
\hline & & CPL/YPPLL & 25.5 & 28.5 & 29.4 & 31 & 26.2 \\
\hline \multirow{2}{*}{$\mathrm{C} 17$} & \multirow{2}{*}{ Small intestine } & CPL/DEATH & 42,618 & 31,844 & 52,841 & 57,020 & 46,256 \\
\hline & & CPL/YPPLL & 30.8 & 23.8 & 38.3 & 41.8 & 33.9 \\
\hline \multirow[b]{2}{*}{$\mathrm{C} 18$} & \multirow{2}{*}{ Colon } & CPL/DEATH & 44,357 & 44,898 & 925,753 & 54,664 & 44,152 \\
\hline & & CPL/YPPLL & 32.1 & 32.5 & 674.3 & 39.7 & 31.7 \\
\hline \multirow{2}{*}{$\mathrm{C} 22$} & \multirow{2}{*}{ Liver } & CPL/DEATH & 45,301 & 42,401 & 50,374 & 50,153 & 38,850 \\
\hline & & CPL/YPPLL & 33.4 & 31.3 & 36.8 & 36.8 & 28.5 \\
\hline \multirow{2}{*}{ C32 } & \multirow{2}{*}{ Laryngeal } & CPL/DEATH & 37,525 & 36,813 & 42,572 & 47,141 & 36,657 \\
\hline & & CPL/YPPLL & 27.6 & 27 & 3 & 34.7 & 27.2 \\
\hline \multirow{2}{*}{ C33-C34 } & \multirow[b]{2}{*}{ Lung } & CPL/DEATH & 36,276 & 39,795 & 46,417 & 47,729 & 38,319 \\
\hline & & CPL/YPPLL & 26.5 & 29.4 & 34.2 & 35.2 & 28.2 \\
\hline \multirow{2}{*}{ C61 } & \multirow{2}{*}{ Prostate } & CPL/DEATH & 24,268 & 24,210 & 35,766 & 31,260 & 26,855 \\
\hline & & CPL/YPPLL & 18.3 & 18.5 & 27.3 & 24.2 & 20.3 \\
\hline \multirow{2}{*}{ C70-C72 } & \multirow{2}{*}{ Brain \& CNS } & CPL/DEATH & 65,029 & 69,169 & 80,467 & 81,709 & 67,247 \\
\hline & & CPL/YPPLL & 47.5 & 50.9 & 58.9 & 59.5 & 48.8 \\
\hline \multirow{2}{*}{ C95-C96 } & Leukaemias of unspecified & CPL/DEATH & 80,891 & 86,112 & 103,203 & 94,468 & 89,507 \\
\hline & cell type & CPL/YPPLL & 61 & 65.5 & 77.9 & 70.5 & 68.2 \\
\hline \multicolumn{8}{|l|}{ Female } \\
\hline \multirow{2}{*}{$\mathrm{c} 15$} & \multirow{2}{*}{ Esophageal } & CPL/DEATH & 8,233 & 7,473 & 13,035 & 11,880 & 9,029 \\
\hline & & CPL/YPPLL & 5.7 & 9.5 & 9.2 & 8.4 & 6.3 \\
\hline \multirow{2}{*}{$\mathrm{c} 16$} & & CPL/DEATH & 10,507 & 13,463 & 14,795 & 15,404 & 11,634 \\
\hline & Stomach & CPL/YPPLL & 7.3 & 10 & 10.3 & 10.9 & 8.2 \\
\hline $\mathrm{C} 17$ & Small intestine & CPL/DEATH & 16,192 & 15,478 & 19,332 & 17,169 & 13,345 \\
\hline C11 & Sintan mitestme & CPL/YPPLL & 11 & 9.8 & 13.4 & 12 & 9.1 \\
\hline $\mathrm{C} 18$ & & CPL/DEATH & 12,527 & 14,728 & 15,375 & 18,831 & 15,068 \\
\hline C18 & Colon & CPL/YPPLL & 8.5 & 13.6 & 10.6 & 13 & 10.5 \\
\hline & & CPL/DEATH & 12,738 & 12,906 & 16,390 & 16,811 & 12,166 \\
\hline $\mathrm{C} 22$ & Liver & CPL/YPPLL & 8.8 & 8.9 & 11.4 & 11.7 & 8.5 \\
\hline & & CPL/DEATH & 11016 & 7626 & 17994 & 16107 & 12909 \\
\hline C33-C34 & Lung & CPL/YPPLL & 7.7 & 11 & 12.5 & 11.4 & 9 \\
\hline $\mathrm{C} 50$ & Breast & CPL/DEATH & 14,046 & 30,850 & 18,446 & 19,947 & 15,045 \\
\hline $\cos 0$ & Breast & CPL/YPPLL & 9.4 & 12.3 & 12.4 & 13.4 & 10 \\
\hline & & CPL/DEATH & 14,352 & 16,127 & 17,571 & 26,933 & 16,407 \\
\hline C53 & Cervix & CPL/YPPLL & 9.7 & 12.8 & 12 & 18.5 & 11 \\
\hline & & CPL/DEATH & 20,282 & 27,352 & 26,929 & 26,703 & 19,748 \\
\hline $\mathrm{C} / 0-\mathrm{C} / 2$ & Brain \& CNS & CPL/YPPLL & 14.2 & 17.3 & 18.7 & 18.6 & 13.7 \\
\hline & & CPL/DEATH & 26,785 & 41,490 & 34,708 & 38,314 & 25,265 \\
\hline C95-C96 & Leukaemias of unspecified cell type & CPL/YPPLL & 19 & 24 & 24.7 & 27.2 & 17.9 \\
\hline
\end{tabular}

combined, gastric cancer had the highest number of YPLL. (Khorasani et al., 2014) Our Findings showed that durig 2006-2010 the total number of YPLLby all cancer site and sex increased except esophageal cancer and Leukaemias of unspecified cell type in males that decreased over period. Over the studied period the total number of YPLL for both sexes combined icreased by $10 \%$.

Our findings showed that the total productivity costs from premature mortality caused by top 10 cancer were about US\$ 1.68 billion between 2006 and 2010. And averege productivity cost per year was about US\$ 337 million for both sexes combined. This study indicated higher total cost of premature mortality in males $(\$ 1,37$ billion vs. $\$ 316$ million) during 2006-2010. Higher mortalitiy, employment and wage rate for males are the reasons of this difference. Similarly, The finding of previous study in Iran showed that the total cost of premature cancer-related mortality for males was $67 \%$ higher than females (Khorasani et al., 2014). furthurmore, in Ireland and the US it was $90 \%$ and $80 \%$ times higher in the males, respectively (Bradley et al., 2008; Hanly and Sharp, 2014). In this study, among males gastric cancer was the most costly cancer in terms of total cost and among females most costly cancer was breast cancer. This finding is in line with that of khosravni et al. previous Iranian studies showed that incidence and mortality of breast cancer are increasing considerably (Taghavi et al., 2012, Rashidian et al., 2013). Based on findings of these reports combined with our results, these cancers are two main areas that should be concidered in cancer prevention programs and priority setting.

An important finding from the study isthat the ranking of cancers by type of mesures was different, for instance, in females, Leukaemias of unspecified cell type ranked 6th in terms of YPLL and 1st in terms of CPL and CPL per YPPLL. In contrast, breast cancer ranked 1st in terms of CPL and $3^{\text {rd }}$ in terms of cost per death and cost per YPPLL. These changes depend on age of death for each cancer 


\section{Behzad Karami-Matin et al}

and survival rate of that. When a cause or disease with low survival rate results in death in earlier age, generally received higher rank of YPLL per death and cost per death (Bradley et al., 2008; Hanly and Sharp, 2014, Khorasani et al., 2014). It implies that prevention policies to reduce cancer-related death can decrease the higher cost and YPLL per death at younger ages.

This study has some limitation, therefore interpreting of results should be based on this limitation. The first is that our analysis was based on data on 29 provinces of Iran, there is no data on Tehran province in this study. It implies that major percentage of deaths did not enter to study. A second limitation is lack of representative data on death and diseases at national level in Iran. And there is remarkable understimation in data on mortality in Iran (Forouzanfar et al., 2014). Third limitation is that this study estimated productivity losses due to premature mortality and other productivity losses because of morbidity that include absenteeism from work, early retirement and reduction in employment did not considere. (Ortiz et al., 2010; Menzin 2012; Doran 2015; Song 2015)

In conclusion, this study shows that premature mortality attributable to cancer has considerable productivity costs. It was about $\$ 1.68$ billion, during 2006-2010 in Iran. In this period the overall cost of productivity losses for the males was 4.3 times higher than the females. Our results also show that gastric cancer (in males) and breast cancer (in females) were the most costly cancers in term of total cost.This finding provide a good picture of economic impact of cancer on society to health system policy/decision makers. It can help them to plan preventive intervention and effective resource allocation.

\section{Acknowledgments}

The authors gratefully acknowledge the Research Council of Kermanshah University of Medical Sciences for the financial support.

\section{References}

Akbarzadehbaghban A, Esmaeili M, Kimiafar K (2009). Medical information management and assessment of direct costs of treatment of lung cancer. Health Information Manage, $\mathbf{5}$, $15-21$.

Bazyar M, Pourreza A, Harirchi I, et al (2012). Medical and non-medical direct costs of cancers in patients hospitalized in Imam Khomeini cancer institution-2010. Hospital, 11, 39-50.

Bradley CJ, YabroffKR, DahmanB, et al (2008). Productivity costs of cancer mortality in the United States: 2000-2020. J Natl Cancer Inst, 100, 1763-70.

Daroudi RA, Akbari SariA, Nahvijou A, et al (2015). The economic burden of breast cancer in Iran. Iran J Public Health, 44, 1225.

Doran CM , Ling R, Byrnes J, et al (2015). Estimating the economic costs of skin cancer in New South Wales, Australia. BMC public health , 1,952.

Forouzanfar MH, Sepanlou SG, Shahraz S, et al (2014). Evaluating causes of death and morbidity in Iran, global burden of diseases, injuries, and risk factors study 2010 . Arch Iran Med, 17, 304-320.

Hanly PA, Sharp L (2014). The cost of lost productivity due to premature cancer-related mortality: an economic measure of the cancer burden. BMC Cancer, 14, 224

Insinga RP (2006). Annual productivity costs due to cervical cancer mortality in the United States. Womens Health Issues, 16, 236-42.

Jemal A, F. Bray, MM. Center, et al (2011). Global cancer statistics. CA Cancer J Clin, 61, 69-90.

Jemal A, Center MM, DeSantis C, et al (2010). Global patterns of cancer incidence and mortality rates and trends. Cancer Epidemiol Biomarkers Prev, 19, 1893-907.

Jonsson B, Wilking N (2007). The burden and cost of cancer. Ann Oncol, 18, 8-22.

Abachizadeh K, Mohagheghi MA, Mosavi-Jarrahi A (2011). Setting research priorities to reduce burden of cancer in Iran: an institutional experience. Asian Pac J Cancer Prev, 12, 2365-70.

Khorasani S, Rezaei S, Rashidian H, et al (2014). Years of potential life lost and productivity costs due to premature cancer-related mortality in Iran. Asian Pac JCancer Prev, 16, 1845-50.

Kim JL, Cho KH, Park EC, et al (2013). A single measure of cancer burden combining incidence with mortality rates for worldwide application. Asian Pac J Cancer Prev, 15, 433-9.

Menzin J, Marton JP, Menzin JA, et al (2012). Lost productivity due to premature mortality in developed and emerging countries: an application to smoking cessation. BMC Med Res Methodol, 12,87.

Naghavi M, Abolhassani F, PourmalekF, et al (2009). The burden of disease and injury in Iran 2003. Popul Health Metr, 7, 9-15.

Ortiz-Ortiz KJ, Perez-Irizarry J, Marín-CentenoH, et al (2010). Productivity loss in Puerto Rico's labor market due to cancer mortality. P R Health Sci J, 29, 241-9.

LozanoR, NaghaviM, Foreman K, et al (2013). Global and regional mortality from 235 causes of death for 20 age groups in 1990 and 2010: a systematic analysis for the Global Burden of Disease Study 2010. Lancet, 380, 2095-2128.

Rashidian H, Davoudi R, Ghiasvand R (2013). Prevalence and Incidence of premenopausal and postmenopausal breast cancer in Iran in 2010. Basic Clinical Cancer Res, 5, 2-10.

Rezaei S, Akbari SariA, ArabM, et al (2015). Estimating economic burden of cancer deaths attributable to smoking in Iran in 2012. J Res Health Sci, 15, 228-33.

Song X, Quek RG, Gandra SR, et al (2015). Productivity loss and indirect costs associated with cardiovascular events and related clinical procedures. BMC Health Serv Res, 1, 254.

Taghavi A, Fazeli Z, Vahedi M (2012). Increased trend of breast cancer mortality in Iran. Asian Pac J Cancer Prev, 13, 367-70.

Torre LA, Bray F, Siegel RL, et al (2015). Global cancer statistics, 2012. CA Cancer J Clin, 65, 87-108. 